\title{
Falls and associated factors among elderly persons residing in the community
}

Danielle Teles da Cruz' Isabel Cristina Gonçalves Leite'

\section{Abstract}

Objective: to identify the prevalence of falls among elderly persons and analyze fall-related factors. Method: a cross-sectional, population-based study conducted by household survey of 400 elderly subjects (aged 60 years or older) living in the city of Juiz de Fora, Minas Gerais, Brazil was carried out. The occurrence of falls in the last 12 months, sociodemographic factors, health profile and geriatric syndromes were observed. The crude and adjusted prevalence ratios (PR) were obtained using Poisson regression. A three-model hierarchical approach was applied in the multivariate analysis. In all the multivariate models, gender and age were defined as confounding variables. Variables which reached a level of $p<0.05$ in the first model were retained in the subsequent models. For all models the significance threshold was set at 0.05 and the variables which remained associated with the occurrence of falls in the $3 \mathrm{rd}$ model were retained in the final analysis. Result: the prevalence of falls was 35.3\% (CI 95\% = 30.7;40.0). Among the elderly persons who reported falls, $44 \%$ reported that they had fallen more than once. The majority of falls occurred at home (69.2\%) and in the morning (46.7\%). Age a reported difficulty walking remained significantly associated with the outcome after adjustments (3rd model). Conclusion: falls are frequent and are associated with increasing age and difficulty walking. The recognition of these factors is important for strategies to reduce falls and the promotion of a healthy aging by means of preventive and rehabilitation actions that target more vulnerable groups.

\footnotetext{
Universidade Federal de Juiz de Fora, Faculdade de Medicina, Departamento de Saúde Coletiva, Programa de pós-graduação em Saúde Coletiva. Juiz de Fora, Minas Gerais, Brasil.

Financiamento: Conselho Nacional de Desenvolvimento Científico e Tecnológico (CNPq), Processo:480163/2012-0.
}

Correspondence

Danielle Teles da Cruz

danitcruz@yahoo.com.br/danielle.teles@ufjf.edu.br
Keywords: Elderly. Accidental Falls. Risk Factors. Cross-Sectional Studies. 


\section{INTRODUCTION}

The growth of the elderly population has created a number of important challenges, such as falls, which are considered a serious public health problem as they affect a large number of elderly people, have significant morbidity and mortality rates and impose a high social and economic cost. They can result in a decline in the functional capacity and quality of life of the elderly and an increased risk of institutionalization ${ }^{1-9}$. While these events are preventable, one alarming statistic stands out: around one third of individuals aged 60 years or over fall at least once a year ${ }^{1,3-6}$.

Falls can result in mild bruising, soft tissue injuries (such as bruises or lacerations), fractures, severe injuries or trauma with or without neurological injury, a need for hospitalization and even death ${ }^{1,2,7,8,10}$. They can also have social and psychological consequences, such as sadness, depression, fear of falling and behavioral changes with a reduction in physical and social activities ${ }^{2,7,8,10}$. Literature describes the existence of a post-fall syndrome characterized by the loss of autonomy, dependence, isolation and depression, a certain degree of immobilization and consequently a greater restriction of daily activities, creating a vicious cycle $\mathrm{e}^{1-3,7,8,10}$.

The identification of factors associated with the occurrence of falls is important for the formulation health prevention and promotion measures, as it allows the identification of the most susceptible segments of the population with the concrete aim of reducing these events and secondary complications. The objective of the present study was therefore to estimate the prevalence of falls in the elderly and to analyze the associated factors.

\section{METHOD}

A cross-sectional study was carried out between October 2014 and March 2015 by means of a household survey, with a sample of 400 elderly persons, aged 60 years or older, living in the North Zone of the city of Juiz de Fora, Minas Gerais (MG), Brazil. This study is part of a larger research project called the Health Survey of the Elderly Population of Juiz de Fora, involving two phases of population-based multidimensional domiciliary surveys (2010/2011 and 2014/2015).

Participants from the first phase of the survey were selected using a multi-stage stratified and randomized sampling process. The primary sampling units were the census tracts. For the drawing of lots, the sectors were grouped into strata defined based on the different modalities of health care to which the population of the sector was assigned, subdivided into Primary Health Care (Family Health Strategy or traditional); Secondary Care and uncovered area. The selection of census tracts was carried out with probabilities proportional to their size (resident population according to data from the Demographic Census 2000) independently in each stratum.

In order to calculate the size of the sample of elderly persons, we considered the prevalence of those who fell at a national level, according to literature, estimated in previous studies as approximately $30 \%{ }^{3,6}$. A maximum error of $5 \%$ was also applied, along with a $95 \%$ confidence level, a correction for finite populations, a sample design effect equal to 1.5 (considering possible stratification and cluster effects, according to the selection process adopted) and possible losses through refusal of approximately $30 \%$.

For the second wave of the survey (2014/2015), the calculation of the sample size was estimated from the data from the previous study and from the results of the 2010 IBGE census relating to the population of the defined area, at the level of census sector disaggregation. There were changes in the population quantitative and distribution of these sectors, which required the resizing of the representative probabilistic sample based on stratification and clustering. In order to neutralize the loss of panel members, who were no longer part of the population surveyed following the years elapsed, the "over sample" method was used, allowing the maintenance of the initial sample, provided that the initial population is known and that the statistical treatment and weighting assignment differs between the groups that make up each situation of loss of the panel member (cases of death, change of address where identification of new address is not possible, long trips away, prolonged hospitalization and entry into a long-term facility) ${ }^{11}$. Age, gender and level of education were selected as variables to define the 
entry of new subjects. Thus, 248 elderly persons from the first phase of 2010 and 175 new elderly persons (a total of 423 elderly persons) made up the 2014 sample. To respect the sample process, noninstitutionalized individuals aged 60 years or older of both genders who were residents of the North Zone of Juiz de Fora, Minas Gerais were included.

The Mini-Mental State Exam (MMSE) was used as a screening tool for cognitive decline, which determined whether another respondent was required. Where another respondent was needed, the questions based on the self-perception of the elderly were not addressed. Researchers state that level of schooling influences performance in the MMSE and adopting stratified cutoff points decreases diagnostic failures, as the schooling of the Brazilian population is diversified and the educational level of the majority of the elderly population is low ${ }^{12}$. However, there is no consensus on the cutoff points to be used in Brazil ${ }^{12}$.

The cut-off point used by the Minas Gerais State Health Department, which makes use of this instrument for the evaluation of the elderly, was therefore adopted ${ }^{13}$. The minimum expected score for elderly persons with four years or more of schooling is 25 points, while for those with less than four years it is 18 points. Lower scores are indicative of cognitive decline. Individuals who presented behavior suggestive of cognitive decline and who were not accompanied by family members and/or caregivers were excluded $(\mathrm{N}=23)$.

The question used to test the outcome variable was: "Have you fallen in the past year?" To support this question, a fall was defined as an accidental event that results in the change in the position of the individual to a lower level, relative to their initial position, with the inability to correct this change in a timely manner and landing on the ground. It results from a total loss of postural balance, due to the sudden insufficiency of the osteoarticular and neural mechanisms essential for maintaining posture ${ }^{14}$.

The independent variables included demographic and socioeconomic conditions, health conditions and geriatric syndromes. The questionnaire used to verify the sociodemographic profile and health issues of the elderly was standardized and pre-tested. The Patient Health Questionnaire-4 (PHQ-4) was used to assess anxiety and depression disorders; the Falls Efficacy Scale - International - Brazil (FES-I) to evaluate fear of falling; the Edmonton Frail Scale (EFS) to verify frailty; and the Lawton and Brody Scale to evaluate functional capacity for the performance of instrumental activities of daily living (IADL).

Intra- and inter-examiner agreement found before the start of data collection was substantial or excellent $(>75 \%)$. During the study the interviewers were monitored, evaluated and refreshed. For the control of the quality of information, field supervision was carried out by the main researchers and around 10\% of data production was reevaluated by a further partial interview at the end of data collection.

The data were processed in a database created using Stata software (SPSS) version 7.0, which allows the characteristics of the sample plan to be considered, with a significance level of $5 \%(p \leq 0.05)$. These data were submitted to descriptive analysis for the extraction of the absolute and relative frequencies of the variables analyzed, as well as the prevalence of the outcome investigated. Crude and adjusted prevalence ratios (PR) were obtained, estimated by Poisson regression.

The theoretical hierarchical approach was used for multivariate analysis ${ }^{16}$. The first model included the demographic and socioeconomic variables (education, ethnicity/skin colour, socioeconomic level according to the Brazilian Association of Research Companies classification, marital status, household arrangement). The second model incorporated the health conditions (presence of reported morbidity, difficulty walking, need for assistance with locomotion, number of medications in continuous use described, presence of caregiver, self-perception of health, anxiety and depression disorders). The third model included geriatric syndromes (Frailty Syndrome, Fear of Falling and Functional Ability to perform IADL). Variables with $p<0.05$ in the first model were retained in the subsequent models, and then for the subsequent levels. Those that remained associated with the occurrence of falls $(p<0.05)$ in the third model were retained in the final analysis (considered to be independently associated with the event). Gender and age were considered a priori confounding variables in the study and were retained in all the multivariate models. 
The Directives and Guidelines Regulating Research Involving Human Beings were followed, in accordance with the provisions of Resolution 466/2012 of the National Health Council. The Ethics Research Committee of the Universidade Federal de Juiz de Fora approved the study (Approval ${ }^{\circ}$ 771/916).

\section{RESULTS}

A total of 400 questionnaires were analyzed, 315 of which were answered by the elderly person themselves and 85 by another respondent. A total of $64.5 \%$ of the sample was made up of women, the mean age was $73.8( \pm 8.02)$ and the educational level was 4.15 years $( \pm 3.40)$. A total of $45.5 \%$ declared themselves to be white, $59.0 \%$ belonged to socioeconomic level C, $55.8 \%$ were married or in a civil partnership, and $89.5 \%$ lived with a partner. Morbidity was verified in $89.0 \%$ of cases, difficulty walking was reported by $42.8 \%$ of the individuals, and $82.0 \%$ stated that they did not require help with locomotion.

The need to continuously take at least one medication was reported by $92.0 \%$ of the sample, while $40.6 \%$ had a caregiver (of whom $95.7 \%$ had family or friends as caregivers). A poor or fair perception of health was reported by $43.5 \%$ of the elderly.
Depression and anxiety disorders were observed in $22.9 \%$ and $27.3 \%$ of the sample, respectively. In terms of geriatric syndromes, $35.7 \%$ of the elderly persons were frail, the majority $(95.7 \%)$ had a fear of falling and $15.5 \%$ were functionally dependent.

The prevalence of falls was $35.3 \%$ (95\% CI=30.7, 40.0). Of those who reported falls, $44.0 \%$ reported having fallen more than once. A total of $46.7 \%$ of falls occurred in the morning and more than half $(62.9 \%)$ occurred at home. Among falls that occurred at home, $21.9 \%$ occurred in the bedroom. The elderly needed help getting up in $56.3 \%$ of cases of falls; there was no loss of consciousness in $88.3 \%$ of falls and in $27.5 \%$ of cases health care was sought due to trauma. Emergency care was the most used health service after the occurrence of a fall and public sector services were used in $68.2 \%$ of cases.

The results of the bivariate analysis of the associations between falls, age, gender, and demographic and socioeconomic variables are shown in Table 1.

Advanced age, lower socioeconomic level and a marital status of widowed were associated with the occurrence of the event. Falls were significantly associated with difficulty walking, need for human assistance with locomotion and having a caregiver (table 2).

Table 1. Falls among the elderly according to demographic and socioeconomic variables. Juiz de Fora, Minas Gerais, 2015.

\begin{tabular}{lllll}
\hline Variable & Participants $(\mathrm{n})$ & Falls $(\%)$ & Gross PR $(\mathrm{CI} 95 \%)$ & $p$ \\
\hline Gender & & & & 0.224 \\
Male & 142 & 61.8 & 1 & \\
Female & 258 & 38.2 & $1.34(0.87 ; 2.08)$ & $<0.001$ \\
\hline Age (Years) & & & & \\
$60-70$ & 157 & 27.4 & 1 & \\
$71-80$ & 149 & 32.9 & $1.30(0.80 ; 2.12)$ & \\
Over 80 & 94 & 52.1 & $2.89(1.70 ; 4.93)$ & \\
Schooling & & & & \\
11 years or more & 29 & 34.5 & 1 & \\
8 to 10 years & 27 & 22.2 & $0.54(0.17 ; 1.78)$ & \\
5 to 7 years & 47 & 34.0 & $0.98(0.37 ; 2.60)$ & \\
1 to 4 years & 248 & 35.9 & $1.06(0.47 ; 2.39)$ & \\
Illiterate & 49 & 40.8 & $1.31(0.51 ; 3.40)$ & \\
& & & & \\
\end{tabular}


Continuation of Table 1

\begin{tabular}{lllll}
\hline Variable & Participants (n) & Falls $(\%)$ & Gross PR (CI 95\%) & $p$ \\
\hline Ethnicity/Skin colour & & & & 0.885 \\
White & 182 & 36.8 & 1 & \\
Black & 57 & 36.8 & $1.00(0.54 ; 1.86)$ & \\
Brown & 132 & 31.8 & $0.80(0.50 ; 1.29)$ & \\
Yellow & 20 & 40.0 & $1.14(0.45 ; 2.94)$ & \\
Indigenous & 9 & 33.3 & $0.86(0.21 ; 3.54)$ & 0.031 \\
Socioeconomic level & & & & \\
A or B & 117 & 29.1 & 1 & 0.029 \\
C & 236 & 36.0 & $2.15(1.07 ; 4.32)$ & \\
D or E & 47 & 46.8 & & \\
Marital status & & & $2.15(1.37 ; 3.37)$ & \\
Married/ civil partnership & 223 & 28.3 & $1.94(0.89 ; 4.23)$ & \\
Widowed & 133 & 45.9 & $1.02(0.31 ; 3.36)$ & \\
Separated or divorced & 30 & 43.3 & & \\
Single & 14 & 28.6 & 1 & \\
Household arrangement & & & $0.91(0.46 ; 1.79)$ & \\
Lives alone & 42 & 33.3 & 35.5 & \\
Lives with other person & 358 & &
\end{tabular}

Table 2. Falls among elderly persons in relation to variables related to health profile. Juiz de Fora, Minas Gerais, 2015.

\begin{tabular}{|c|c|c|c|c|}
\hline Variable & Participants (n) & Fall $(\%)$ & Gross PR (CI 95\%) & $p$ \\
\hline Reported morbidity & & & & 0.501 \\
\hline No & 44 & 29.5 & 1 & \\
\hline Yes & 356 & 36.0 & $1.34(0.68 ; 2.65)$ & \\
\hline Difficulty walking & & & & 0.001 \\
\hline No & 229 & 28.4 & 1 & \\
\hline Yes & 171 & 44.4 & $2.02(1.33 ; 3.06)$ & \\
\hline Need for help with locomotion & & & & 0.037 \\
\hline No & 328 & 32.3 & 1 & \\
\hline Human help & 30 & 56.7 & $2.74(1.28 ; 5.85)$ & \\
\hline Assistance Aid & 42 & 42.9 & $1.57(0.82 ; 3.02)$ & \\
\hline Continuous use of medication & & & & 0.387 \\
\hline None & 32 & 25.0 & 1 & \\
\hline 1 to 4 medications & 203 & 36.0 & $1.69(0.72 ; 3.94)$ & \\
\hline More than 4 medications & 165 & 36.4 & $1.71(0.73 ; 4.05)$ & \\
\hline Presence of caregiver & & & & 0.015 \\
\hline No & 238 & 30.3 & 1 & \\
\hline Yes & 162 & 42.6 & $1.71(1.13 ; 2.59)$ & \\
\hline Perception of health ${ }^{\mathrm{a}}$ & & & & 0.093 \\
\hline Excellent / Very good / Good & 178 & 30.3 & 1 & \\
\hline Fair / Poor & 137 & 39.4 & $1.49(0.94 ; 2.39)$ & \\
\hline Anxiety disorders ${ }^{a}$ & & & & 0.997 \\
\hline No & 229 & 34.1 & 1 & \\
\hline Yes & 86 & 34.9 & $1.04(0.62 ; 1.75)$ & \\
\hline Depression disorders ${ }^{a}$ & & & & 0.929 \\
\hline No & 243 & 34.2 & 1 & \\
\hline Yes & 72 & 34.7 & $1.03(0.59 ; 1.78)$ & \\
\hline
\end{tabular}

${ }^{a}$ Variables investigated only when the elderly person themselves responded. 
Significant gross prevalence ratios were observed for the presence of frailty and partial dependence in performing IADL (Table 3).
The results of the multivariate analysis of the factors associated with the occurrence of falls are shown in table 4.

Table 3. Falls among the elderly according to geriatric syndromes. Juiz de Fora, Minas Gerais, 2015.

\begin{tabular}{lllll}
\hline Variable & Participants (n) & Falls (\%) & Gross PR (CI 95\%) & $p$ \\
\hline Frailty Syndrome $^{\mathrm{a}}$ & & & & 0.002 \\
No & 222 & 29.7 & 1 & \\
Yes & 117 & 47.0 & $2.10(1.32 ; 3.33)$ & 0.524 \\
\hline Fear of falling & & & & \\
No & 15 & 26.7 & 1 & 0.032 \\
Yes & 300 & 34.7 & $1.46(0.45 ; 4.70)$ & \\
Functional capacity for the performance of IADL & & & & \\
Independent & 338 & 32.5 & 1 & \\
Partial dependency & 53 & 52.8 & $2.32(1.29 ; 4.17)$ & \\
Significant dependency & 338 & 32.5 & $1.04(0.25 ; 4.22)$ & \\
\hline
\end{tabular}

${ }^{a}$ Variable investigated in accordance with Edmonton Frail Scale.

${ }^{\mathrm{b}}$ Variables investigated only when the elderly persons themselves responded.

Table 4. Results of multivariate analysis of factors associated with falls among the elderly. Juiz de Fora, Minas Gerais, 2015.

\begin{tabular}{|c|c|c|c|c|c|c|}
\hline Variable & $\begin{array}{l}\text { Model 1a } \\
\text { PR (CI95\%) }\end{array}$ & $\mathrm{p}$ & $\begin{array}{l}\text { Model 2b } \\
\text { PR }(\text { CI95\%) }\end{array}$ & $\mathrm{P}$ & $\begin{array}{l}\text { Model 3c } \\
\text { PR }(\text { CI95\%) }\end{array}$ & $\mathrm{p}$ \\
\hline Gender & & 0.575 & & 0.222 & & 0.509 \\
\hline Male & 1 & & 1 & & 1 & \\
\hline Female & $1.15(0.70 ; 1.89)$ & & $0.75(0.48 ; 1.19)$ & & $0.85(0.52 ; 1.38)$ & \\
\hline Age (years) & & 0.003 & & 0.003 & & 0.007 \\
\hline $60-70$ & 1 & & 1 & & 1 & \\
\hline $71-80$ & $1.20(0.70 ; 2.00)$ & & $1.28(0.78 ; 2.08)$ & & $2.20(1.21 ; 4.03)$ & \\
\hline Over 80 & $2.50(1.37 ; 4.55)$ & & $2.43(1.37 ; 4.35)$ & & $2.34(1.26 ; 4.35)$ & \\
\hline Socioeconomic level & & 0.152 & & & & \\
\hline $\mathrm{A}$ or $\mathrm{B}$ & 1 & & & & & \\
\hline $\mathrm{C}$ & $0.76(0.46 ; 1.26)$ & & & & & \\
\hline $\mathrm{D}$ or $\mathrm{E}$ & $0.59(0.28 ; 1.22)$ & & & & & \\
\hline Marital status & & 0.084 & & & & \\
\hline Married or civil partnership & 1 & & & & & \\
\hline Widowed & $0.64(0.37 ; 1.01)$ & & & & & \\
\hline Separated or Divorced & $0.49(0.22 ; 1.10)$ & & & & & \\
\hline Single & $0.83(0.24 ; 2.81)$ & & & & & \\
\hline Difficulty walking & & & & 0.037 & & 0.050 \\
\hline No & & & 1 & & 1 & \\
\hline Yes & & & $1.67(1.03 ; 2.70)$ & & $1.69(1.00 ; 2.85)$ & \\
\hline Need for help with locomotion & & & & 0.385 & & \\
\hline No & & & 1 & & & \\
\hline Human help & & & $0.69(0.30 ; 1.60)$ & & & \\
\hline Assistance Aid & & & $1.07(0.51 ; 2.25)$ & & & \\
\hline
\end{tabular}


Continuation of Table 3

\begin{tabular}{|c|c|c|c|c|c|c|}
\hline Variable & $\begin{array}{l}\text { Model 1ª } \\
\text { PR (CI95\%) }\end{array}$ & $\mathrm{p}$ & $\begin{array}{l}\text { Model } 2^{\mathrm{b}} \\
\text { PR (CI95\%) }\end{array}$ & $\mathrm{P}$ & $\begin{array}{l}\text { Model 3c } \\
\text { PR (CI95\%) }\end{array}$ & $\mathrm{p}$ \\
\hline Presence of caregiver & & & & 0.725 & & \\
\hline No & & & 1 & & & \\
\hline Yes & & & $0.92(0.56 ; 1.49)$ & & & \\
\hline Frailty Syndrome & & & & & & 0.407 \\
\hline No & & & & & 1 & \\
\hline Yes & & & & & $0.77(0.42 ; 1.42)$ & \\
\hline $\begin{array}{l}\text { Functional capacity for } \\
\text { realization of IADL }\end{array}$ & & & & & & 0.476 \\
\hline Independent & & & & & 1 & \\
\hline Partial dependence & & & & & $0.89(0.42 ; 1.91)$ & \\
\hline Significant dependence & & & & & $1.77(0.37 ; 8.47)$ & \\
\hline
\end{tabular}

${ }^{a}$ Socioeconomic and demographic variables

${ }^{\mathrm{b}}$ Socioeconomic and demographic variables plus health profile

c Socioeconomic and demographic variables, health profile plus geriatric syndromes

After all the adjustments (model 3), age and reported difficulty walking remained significantly associated with the outcome.

\section{DISCUSSION}

The prevalence of falls in the studied population was $35.3 \%$, similar to that found in Brazilian literature ${ }^{3-6,15,16}$. Mota et al. ${ }^{16}$, in a study with a sample of 1,064 elderly persons, found a prevalence of $30.3 \%$ for the outcome. In another study conducted in seven Brazilian states with elderly people aged 65 years or over, the prevalence of falls was $34.8 \% \%^{5}$. Soares et al. ${ }^{17}$ estimated a prevalence of $37.5 \%$ among elderly people living in the community in the city of Cuiabá, Mato Grosso. Siqueira et al. ${ }^{6}$ calculated a prevalence of falls of $27.6 \%$ in a cross-sectional study with a sample of 6,616 elderly people living in urban areas of 100 municipalities distributed across 23 Brazilian states. However, this study revealed a significant variation in the prevalence of falls between geographic regions, with the extremes in the southeast $(30.0 \%)$ and the north $(18.6 \%)$.

Different prevalences to those found in the present study have been reported in literature ${ }^{7,9,18,19}$. These differences can be attributed to the design of the studies, the characteristics of the sample, the methodologies adopted or because they are specific estimates with a margin of error. Pereira et al. ${ }^{19}$ also adds that the significant differences in the prevalence of falls can be explained by the lack of a consensual definition for the event, which may lead to different interpretations by the elderly. The study by Pereira et al. ${ }^{19}$, which was conducted in southern Brazil, asked whether the elderly person fell on the floor.

Among those who reported falling, 44.0\% described having fallen more than once, indicating the recurrent nature of this event among the elderly ${ }^{2,49,10,15,18,20}$. This observation is important as it is based on the recognition that a history of falls is a risk factor for future falls ${ }^{2,21}$ and that a greater number of falls increases the probability of a future event resulting in fracture $e^{4,22}$. Most of the falls occurred in the own home of the elderly persons and in the morning. According to data from the Ministry of Health ${ }^{1}$ and other studies ${ }^{7,910,20}$ a large proportion of accidental falls occur indoors or nearby during routine activities such as walking, changing position and going to the toilet. For Antes et al. ${ }^{7}$ a greater number of falls occur in the morning as it is the time of day when the elderly person performs routine tasks, such as domestic activities.

Several studies corroborate the findings of the present study, namely that the occurrence of falls was associated with age ${ }^{2,3,5,9,10,15-18,21,23}$ and difficulty walking $23,9,20,21,24,25$. These factors are closely related, as the aging process has repercussions on structural and functional disorders capable of modifying mobility patterns and the relation of the individual to the environment ${ }^{26-28}$. 
As the years pass, the importance of environmental factors in explaining the way in which elderly individuals perform their social relations and everyday interactions increases, as well as the different forms of illness and negative outcomes in health ${ }^{19}$. In the absence of an environment that optimizes their potential, the elderly end up limiting their activities, which within a cascade of events augments the disorders arising from the biological aging process.

With advancing age, there is reduction of muscle strength and elasticity, a decrease in bone mass, impairment of joint stability and dynamics, and sensory, vestibular and somatosensory and nervous system disorders. This set of modifications has an impact on the mechanisms of postural control, leading to disturbances in gait, balance and posture. This cascade of changes, besides making it difficult to carry out activities of daily living, predisposes the elderly to falls ${ }^{2,21,24-28}$.

Elderly persons suffer a decline in the ability to detect and control the back and forth oscillation of the body and also an increase in oscillation, both with their eyes open and closed; a reduction in the perception of joint movement and proprioceptive loss. These factors have been identified as key elements for postural control in an upright position and for locomotion capacity ${ }^{25,26,29}$. The consequences of these changes, allied to others such as cognitive decline, reduced nerve conduction speed and declining strength and muscle tone, cause the elderly to acquire more conservative gait patterns ${ }^{25,26,29}$.

This conservative gait pattern is characterized by a slower than usual gait speed, shorter pitch length and height, an increased support base and time spent in the double support phase; and increased cadence in situations where an increase in walking speed is required. These adaptations that occur with aging are considered a compensatory process that seeks to maximize stability and promote greater safety. In situations in which balance is disturbed, elderly individuals are less able to perform reactions that lead to the resumption of balance and avoid the occurrence of falls. They are less able to displace body weight and take quick steps or change their trajectory, have difficulty initiating reactions with the upper limbs and a reduced ability to reach and quickly grasp something that can support them and avoid falls. It is worth reporting that the described condition is even more pronounced in elderly persons with a history of falls $2,24,25,29$.

In this analysis, it should be pointed out that the changes that occur within the aging process do not directly and necessarily result in disease, but the probability of its onset increases with age, due to vulnerability to pathological processes and difficulty in maintaining homeostasis ${ }^{27,31}$. Thus, aging is an agent that modifies and at the same time is modified by the presence of a certain health condition. Within this perspective, difficulty walking may be a consequence of the process of senescence or the synergistic action between this process and the main actions of this phase of life.

Although not explored in the present study, the results encourage a discussion about the importance of the practice of physical activity as an effective tool for coping with major geriatric syndromes. Literature shows that the practice of regular physical activity can minimize the deleterious effects of aging, contributes to the maintenance and/or improvement of muscular strength, body balance, coordination and speed of movement, cognitive ability and also functional ability ${ }^{9,32,33}$. It is therefore a powerful strategy for the prevention of falls in the elderly population ${ }^{5,9,33}$.

The aging process and its main tangential aspects, such as falls, are the result of a complex interaction of several factors that reflect biological aspects and genetic heritage, but also the cumulative impact of these factors, linked to environmental and social issues, which translate into inequalities and inequities in health. This complex network of interactions heightens the need for interdisciplinary and crossdomain interventions and approaches. Age and walking difficulty were factors associated with falls in the present study.

Although age is considered a non-modifiable risk factor, two reflections should arise on this result: it is possible to promote healthy aging for future generations in a planned manner, while it is essential to develop actions that reduce negative impacts of aging and optimize quality of life for those already in this phase of life. Due to the cross-sectional design of this research, it is not possible to make inferences about the causality of the association in relation to the difficulty in walking reported by the elderly. However, it is worth reporting that, regardless of causality, 
walking difficulty can be considered a modifiable risk factor, which requires action involving the individual and the environment. These actions should occur both individually and collectively, in order to reduce barriers and circumstances that make locomotion even more challenging for the elderly and increase the risk of falls.

It should be emphasized that the present study was conducted with high levels of methodological rigor; that the necessary precautions in the sampling process were considered; and that similar results in literature were provided. Considering the use of sample weighting, there would be little variation in the estimated parameters even if the sample were expanded.

\section{REFERENCES}

1. Brasil. Ministério da Saúde. Envelhecimento e saúde da pessoa idosa. Brasília, DF: Ministério da Saúde; 2006.

2. Ambrose AF, Paul G, Hausdorff JM. Risk factors for falls among older adults: a review of the literature. Maturitas. 2013;75(1):51-61.

3. Cruz DT, Ribeiro LC, Vieira MT, Teixeira MTB, Bastos RR, Leite ICG. Prevalência de quedas e fatores associados em idosos. Rev Saúde Pública. 2012;46(1):138-46.

4. Perracini MR, Ramos LR. Fatores associados a quedas em uma coorte de idosos residentes na comunidade. Rev Saúde Pública. 2002;36(6):709-16.

5. Siqueira FV, Facchini LA, Piccini RX, Tomasi E, Thumé E, Silveira DS, et al. Prevalência de quedas em idosos e fatores associados. Rev Saúde Pública. 2007;41(5):749-56.

6. Siqueira FV, Facchini LA, Silveira DS, Piccini RX, Tomasi E, Thumé E, et al. Prevalência de quedas em idosos no Brasil: uma análise nacional. Cad Saúde Pública. 2011;27(9):1819-26.

7. Antes DL, d'Orsi E, Benedetti TRB. Circunstâncias e consequências das quedas em idosos de Florianópolis. Epi Floripa Idoso 2009*. Rev Bras Epidemiol. 2013;16(2):469-81.

8. Falsarella GR, Gasparotto LPR, Coimbra AMV. Quedas: conceitos, frequências e aplicações à assistência ao idoso: revisão da literatura. Rev Bras Geriatr Gerontol [Internet]. 2014 [acesso em $01 \mathrm{fev}$. 2018];17(4):897-910. Disponível em: http://www. scielo.br/scielo.php?script $=$ sci_abstract $\&$ pid $=$ S180998232014000400897\&lng=en\&nrm=iso\&tlng=pt

\section{CONCLUSION}

Falls are frequent events among the elderly and have been associated with increasing age and reporting difficulty walking. The identification of these factors allows the recognition of the groups that are most susceptible to the occurrence of this outcome and consequently offers important support for the elaboration and planning of government policies, actions and strategies to address this serious public health problem. Faced with an aging population and the new demands emerging from this phenomenon, it is imperative to overcome the paradigms that affect the elderly and to adopt a more equanimous and attentive vision of the health of these individuals.

9. Rodrigues IG, Fraga GP, Barros MBA. Quedas em idosos: fatores associados em estudo de base populacional. Rev Bras Epidemiol. 2014;17(3):705-18.

10. Cavalcante ALP, Aguiar JB, Gurgel LA. Fatores associados a quedas em idosos residentes em um bairro de Fortaleza, Ceará. Rev Bras Geriatr Gerontol. 2012;15(1):137-46.

11. Rahman MM, Davis DN. Addressing the class imbalance problem in medical datasets. Int J Mach Learn Comput. 2013;3(2):224-8.

12. Melo DM, Barbosa AJG. O uso do Mini-Exame do Estado Mental em pesquisas com idosos no Brasil: uma revisão sistemática. Ciênc Saúde Colet. 2015;20(12):3865-76.

13. Minas Gerais. Secretaria de Saúde. Manual do prontuário de saúde da família. Belo Horizonte: SES/ MG; 2008.

14. Paixão Júnior CM, Heckman MF. Distúrbios da postura, marcha e quedas. In: Freitas EV, Py L, editores. Tratado de geriatria e gerontologia. $4^{\mathrm{a}} \mathrm{ed}$. Rio de Janeiro: Guanabara Koogan; 2016. p. 1031-43.

15. Fhon JRS, Wehbe SCCF, Vendruscolo TRP, Stackfleth R, Marques S, Rodrigues RAP. Quedas em idosos e sua relação com a capacidade funcional. Rev Latinoam Enferm. 2013;20(5):1-8.

16. Motta LB, Aguiar AC, Coutinho ESF, Huf G. Prevalência e fatores associados a quedas em idosos em um município do Rio de Janeiro. Rev Bras Geriatr Gerontol. 2010;13(1):83-91. 
17. Soares WJS, Moraes SA, Ferriolli E, Perracini MR. Fatores associados a quedas e quedas recorrentes em idosos: estudo de base populacional. Rev Bras Geriatr Gerontol. 2014;17(1):49-60.

18. Nascimento JS, Tavares DMS. Prevalência e fatores associados a quedas em idosos. Texto \& Contexto Enferm [Internet]. 2016 [acesso em 01 dez. 2018];25(2):2-9. Disponível em: http://www. scielo.br/scielo.php?script $=$ sci_abstract\&pid $=$ S0104$07072016000200312 \& \operatorname{lng}=$ en\&nrm $=$ iso\&tlng $=$ pt

19. Pereira GN, Morsch P, Lopes DGC, Trevisan MD, Ribeiro A, Navarro JHN, et al. Social and environmental factors associated with the occurrence of falls in the elderly. Ciênc Saúde Coletiva. 2013;18(12):3507-14.

20. Silva A, Faleiros HH, Shimizu WAL, Nogueira LM, Nhãn LL, Silva BMF, et al. Prevalência de quedas e de fatores associados em idosos segundo etnia. Ciênc Saúde Colet. 2012;17(8):2181-90.

21. Deandrea S, Lucenteforte E, Bravi F, Foschi R, La Vecchia C, Negri E. Risk factors for falls in community-dwelling older people: a systematic review and meta-analysis. Epidemiology. 2010;21(5):658-68.

22. Edwards MH, Jameson K, Denison H, Harvey NC, Sayer AA, Dennison EM, et al. Clinical risk factors, bone density and fall history in the prediction of incident fracture among men and women. Bone. 2013;52(2):541-7.

23. Grundstrom AC, Guse CE, Layde PM. Risk factors for falls and fall-related injuries in adults 85 years of age and older. Arch Gerontol Geriatr. 2012;54(3):421-8.

24. Cebolla EC, Rodacki ALF, Bento PCB. Balance, gait, functionality and strength: comparison between elderly fallers and non-fallers. Braz J Phys Ther. 2015;19(2):146-51.
25. Borel L, Alescio-Lautier B. Posture and cognition in the elderly: interaction and contribution to the rehabilitation strategies. Neurophysiol Clin. 2014;44(1):95-107.

26. Rosso AL, Studenski SA, Chen WG, Aizenstein HJ, Alexander NB, Bennett DA, et al. Aging, the central nervous system, and mobility. J Gerontol Ser A Biol Sci Med Sci. 2013;68(11):1379-86.

27. Moraes EN, Moraes FL, Lima S. Características biológicas e psicológicas do envelhecimento. Rev Med Minas Gerais. 2010;20(1):67-73.

28. Brady AO, Straight CR, Evans EM. Body composition, muscle capacity, and physical function in older adults: an integrated conceptual model. J Aging Phys Act. 2014;22(3):441-52.

29. Novaes RD, Miranda AS, Dourado VZ. Velocidade usual da marcha em brasileiros de meia idade e idosos. Braz J Phys Ther. 2011;15(2):117-22.

30. World Health Organization. World report on ageing and health. Geneva: World Health Organization; 2015.

31. Teixeira INDO, Guariento ME. Biologia do envelhecimento: teorias, mecanismos e perspectivas. Ciênc Saúde Colet. 2010;15(6):2845-57.

32. Cordeiro J, Castillo D, Lencina B, Freitas CS, Gonçalves MP. Effects of physical activity in declarative memory, functional capacity and quality of life in elderly. Rev Bras Geriatr Gerontol. 2014;17(3):541-52.

33. Merom D, Pye V, Macniven R, van der Ploeg H, Milat A, Sherrington C, et al. Prevalence and correlates of participation in fall prevention exercise/physical activity by older adults. Prev Med. 2012;55(6):613-7. 